\title{
PINTURA DE PAISAGENS AMAZÔNICAS: O DESIGN VERNACULAR EM MOSQUEIRO (PA)
}

\author{
Painting of Amazon landscapes: the vernacular design in \\ Mosqueiro (PA) \\ Pintura de paisajes amazónicos: el diseño vernacular en \\ Mosqueiro (PA)
}

\author{
Natália Cristina Rodrigues Pereira \\ Universidade Federal do Pará, Pará, Brasil. \\ Mestre em Ciências da Comunicação pelo Programa de Pós-graduação Comunicação, Cultura e \\ Amazônia (PPGCom-UFPa). Pesquisadora do Grupo de Pesquisa Mídias Alternativas na Amazônia \\ (UFPa-CNPq) \\ E-mail: nataliacrpereira@gmail.com
}

\section{Célia Regina Trindade Chagas Amorim}

\begin{abstract}
Universidade Federal do Pará, Pará, Brasil.
Pesquisadora em pós-doutoramento na Universidade de Coimbra, Portugal. Núcleo de estudos: Democracia, Cidadania e Direito do Centro de Estudos Sociais (CES). Professora doutora do PPGCom/Facom da UFPa. Coordenadora do projeto Cidadania comunicativa: desafios, lutas e direitos compartilhados na Amazônia. Coordenadora do Grupo de Pesquisa Mídias Alternativas na Amazônia (UFPa-CNPq).

Email: celia.trindade.amorim@gmail.com
\end{abstract}

RESUMO A experiência comunicacional e estética na Amazônia chamada de design vernacular faz parte das reflexões deste artigo. Trata-se de desenhos de letras, ilustrações e paisagens pintados à mão que, baseados na cultura popular, objetivam suprir as necessidades comunicacionais do comércio informal onde se originam. Parte-se da seguinte inquietação: De que forma o design vernacular, na sua modalidade paisagística, expressa a cultura amazônica? Exploram-se os conceitos de mediação e midiatização, e como estes influenciam as pinturas locais. A pesquisa se apoiou em Martín-Barbero, Hepp, Hjarvard, Trindade e Perez, Martino, dentre outros.

PALAVRAS-CHAVE Design vernacular, Comunicação, Pintura de paisagens, Midiatização, Amazônia.

\begin{abstract}
The communicational and aesthetic experience in the Amazon, called vernacular design at the Academy, is part of the reflections of this study. These are drawings of letters, illustrations and hand-painted landscapes that, based on popular culture, aim to meet the communication needs of the informal trade from where they originate. The following concern arises: How does the vernacular design, in its landscape mode, express the Amazonian culture? The concepts of mediation and mediatization are explored, and also how they influence local paintings. The research was based on Martín-Barbero, Hepp, Hjarvard, Trindade e Perez, Moreira, Martino, among others.
\end{abstract}

KEYWORDS Vernacular design, Communication, Landscape paintings, Mediatization, Amazon. 
RESUMEN La experiencia comunicacional y estética en la Amazonia, llamada de diseño vernacular en la Academia, forma parte de las reflexiones de este artículo. Se trata de dibujos de letras, ilustraciones y paisajes pintados a mano que, basados en la cultura popular, objetivan suplir las necesidades comunicacionales del comercio informal donde se originan. Se parte de la siguiente inquietud: ¿De qué forma el diseño vernacular, en su modalidad paisajística, expresa la cultura amazónica? Se exploran los conceptos de mediación y mediatización, y cómo influencian las pinturas locales. La investigación se apoyó en Martín-Barbero, Hepp, Hjarvard, Trindade y Perez, Moreira, Martino, entre otros.

PALABRAS CLAVE Diseño vernacular, Comunicación, Pintura de paisajes, Mediatización, Amazonia.

\section{INTRODUÇÃO}

Este artigo, ao fazer um recorte de uma pesquisa de mestrado ${ }^{1}$ que estudou estética e comunicação, amplia o debate sobre o design vernacular na Amazônia para os estudos da midiatização, importantes para compreender a inserção e o impacto das mídias no cotidiano regional (HEPP, 2014; HJARVARD, 2014; TRINDADE; PEREZ, 2016).

Design vernacular, como será mais desenvolvido no artigo, é a forma como são academicamente conhecidos os desenhos de letras, ilustrações e paisagens pintados manualmente em fachadas, placas, muros, faixas e outras superfícies espalhadas pela região. Baseados na cultura popular, esses elementos objetivam suprir as necessidades comunicacionais do comércio informal onde se originam, sendo, portanto, importantes para as comunidades locais.

A base empírica da pesquisa localiza-se na ilha de Mosqueiro, município de Belém do Pará, Brasil, localidade com forte teor turístico pelo potencial da natureza, que permite contato com praias e rios amazônicos, mas também possui proximidade geográfica com a capital, contando inclusive com transporte público que realiza o trajeto de Belém para a ilha e vice-versa.

Ao longo do artigo, discute-se a cultura da pintura de paisagens. $\mathrm{O}$ pesquisador Eidorfe Moreira (2012, p. 171) explica: "quer em nossas atividades práticas, quer em nossos devaneios ou ilusões, vivemos e gravitamos em funções de paisagens”. Isso significa que, segundo o autor, o homem se relaciona não apenas com a paisagem real, concreta, que lhe chega através dos sentidos, mas também com a paisagem ideal, ligada aos seus sonhos e devaneios, uma paisagem imaginada. Trazendo esse pensamento para a discussão realizada neste artigo, observa-se que as paisagens podem ser representadas no cotidiano por meio da arte, da pintura, da música, e também a partir das representações da natureza amazônica criadas pelos pintores de letras nos desenhos vernaculares.

Com base nessas percepções, partiu-se da seguinte pergunta: De que forma o design vernacular, a partir do desenho de paisagens em Mosqueiro, expressa a cultura amazônica? Para o embasamento teórico, utilizou-se Moreira (2012), Martino (2007), Amaral Filho (2016), dentre outros. Abordaram-se também os conceitos de mediação e midiatização a partir de autores como Hepp (2014), Hjarvard (2015, 2014), Trindade

1. Dissertação intitulada Design vernacular: a comunicação visual informal no cotidiano da Amazônia (2018), de autoria de Natália Cristina Rodrigues Pereira e orientada pela Prof. ${ }^{a}$ Dra. Célia Regina Trindade Chagas Amorim, para o Programa de Pós-graduação Comunicação, Cultura e Amazônia (PPGCom-UFPa). 
e Perez (2016) e Martín-Barbero (2009, 2004). Além da pesquisa bibliográfica, foi realizada pesquisa de campo de caráter qualitativo em 18 de novembro de 2017 em Mosqueiro, Pará, onde foram registradas fotografias e realizadas conversas informais com a comunidade local. Assim, o artigo apresenta uma breve descrição sobre o design vernacular e a localidade estudada, refletindo e analisando as pinturas de paisagens a partir da ótica da estética, da comunicação e da midiatização.

\section{REFLEXÕES SOBRE O DESIGN VERNACULAR}

O design vernacular é uma forma de comunicação visual informal que geralmente envolve a criação de uma tipografia manual - a tipografia seria o modo como se organizam as ideias por meio da existência de um código comunicativo alfabético. É utilizado para divulgar produtos e serviços ofertados no comércio onde se origina.

Trata-se de pinturas que possuem características específicas, como o enraizamento na cultura popular, o uso intenso de cores primárias, a criação artesanal e manual, o aprendizado que ocorre geralmente por meio da oralidade, dentre outros (MARTINS, 2008; PEREIRA; 2014; PEREIRA; AMORIM, 2016). Está presente nas cidades amazônicas através de seu uso em pinturas feitas à mão em barcos, placas, residências, mercados, lojas, faixas, bandeiras de açaí, cartazes de supermercados e diversas plataformas locais.

Na região observou-se que, além do uso da tipografia, existe também uma abundância na criação de ilustrações e paisagens que se unem na visualidade do vernacular. Ou seja, percebeu-se durante a pesquisa ser necessário alargar o entendimento para os elementos comunicacionais vernaculares que vão além de sua estrutura tipográfica e auxiliam na construção da mensagem que o pintor deseja transmitir, como, por exemplo, as paisagens da natureza criadas pelos pintores de letras. Estes últimos, percebidos durante a pesquisa nas ilhas, remetem às imagens presentes no imaginário sobre o que é a vida na Amazônia.

Uma das facetas poéticas dessa forma de comunicação está relacionada ao trabalho manual informal realizado pelos pintores (ou abridores) de letras, que preenchem tais elementos de vida, cores e detalhes que as diferenciam das pinturas criadas por outros pintores ou mesmo desenvolvidas em outras partes do país. Essa forma de comunicação se alimenta da cultura local ao se basear na imaginação e subjetividade do pintor, mas também no imaginário da comunidade, no modo como as pessoas se comunicam, nas necessidades da população junto à qual o design vernacular é criado.

Porém é importante lembrar que, da mesma forma que essa comunicação se alimenta da cultura local, ela também encontra fontes de inspiração e ecos em outras culturas, meios de comunicação e novas tecnologias. Ela não está isolada em si mesma, nem no campo geográfico nem no campo das ideias, como será observado ao longo do trabalho.

\section{EXPERIÊNCIA ESTÉTICA E COMUNICAÇÃO}

A palavra estética origina-se do grego aisthesis, que tem a ver com a sensibilidade, com aquilo que é sensível. O conceito atual de estética remete ao estudo filosófico da obra de arte. Contudo, assim como Martino (2007, p. 11), entende-se aqui o conceito de estética em seu sentido amplo, 
como "uma atividade dos sentidos relacionada [...] com as possibilidades mentais de atividade. [...] Pensar as relações entre os meios de massa e o indivíduo como um exercício de sensibilidade e produção - uma aisthesis geradora de uma poiesis". Dito de outra forma, uma sensibilidade geradora, união entre razão e emoção capaz de criar alguma coisa.

Nas palavras de Martino (2007), a "Estética da Comunicação mostra as transformações no indivíduo e no cotidiano a partir da comunicação e esta ocupa todos os lugares, isto é, todos os espaços da vida cotidiana são preenchidos por relações de comunicação" (p. 9). Códigos comunicativos estão em todo lugar, seja na televisão, no rádio, nos jornais, nos muros pela cidade, nos barcos amazônicos, nas redes sociais, ao alcance de todos. Além disso, para o autor, tais códigos não configuram um fluxo de comunicação unilateral, baseada no emissor-mensagem-receptor. Ao contrário, ao tratar de uma atividade mental efetivada na relação social, enfatiza-se o aspecto intersubjetivo da comunicação.

Quando uma pessoa olha para o design vernacular e apresenta sensações a partir dessa interação, como sensações de gosto, sejam elas positivas ou negativas, trata-se de uma experiência estética. Assim, partese do pressuposto de que o design vernacular está centrado em um rio de sentidos e códigos comunicacionais particulares, camuflados no cotidiano, e cuja experiência social também se dá a partir de uma experiência estética. Por fim, cabe aqui discutir um pouco mais sobre o próprio conceito de paisagem. Para o pensador Eidorfe Moreira, a concepção de paisagem se entrelaça com a de cultura, como algo que reflete o fazer humano. Em suas palavras, "a cultura é uma expressão geomorfológica, uma verdadeira camada constitutiva do Planeta, e nesse caráter toma parte saliente na sua economia vital" (MOREIRA, 2012, p. 70), afinal de contas, trata-se do "conjunto das superações e das conquistas do homem sobre a Natureza" (Ibidem, p. 71). Ou seja, o geógrafo entende a cultura como as mudanças, positivas ou negativas, realizadas pelo homem sobre a paisagem. Assim, a geografia e as paisagens existem em contato com o homem, com sua atuação no lugar que habita.

Levando em consideração o conceito de paisagem ideal do autor, uma paisagem imaginada que influenciou a história da Amazônia foi a do mito do Eldorado, por exemplo, que refletia ambições econômicas, uma abundância de riquezas e aventuras (Ibidem, p. 174). Durante séculos acreditou-se que se encontraria uma imensidão de ouro na região amazônica, e isso potencializou as políticas de colonização para a região. Isso assinala que, mesmo existindo em um plano imaginado, abstrato, as paisagens ideais conseguem influenciar ações e políticas concretas ao se colocarem enquanto uma possível verdade.

\section{MIDIATIZAÇÃO: AMAZÔNIA E IMAGINÁRIOS}

Conforme citado anteriormente, os códigos comunicativos se espalham pela vida social (MARTINO, 2007) e cada vez mais a tecnologia possui um papel importante nesse contexto. Às vezes é tentador pensar o objeto de pesquisa enquanto algo contido nele mesmo; nesse caso, olhar para as pinturas de paisagens e enxergar apenas uma inspiração regional, ribeirinha, uma cultura específica e o que ela tem de intocado. Contudo, a vida cotidiana das pessoas que vivenciam essa forma de comunicação é marcada por entrelaçamentos com outros meios de comunicação e outras experiências sociais; por isso é preciso discutir o conceito de midiatização e como este se reflete no design vernacular. 
No cenário internacional, Andreas Hepp (2014) realiza um panorama geral sobre o conceito de midiatização, que seria "o conceito usado para analisar a inter-relação (de longo prazo) entre a mudança da mídia e da comunicação, por um lado, e a mudança da cultura e da sociedade, por outro, de maneira crítica” (p. 51). Um ponto importante da argumentação de Hepp (2014, p. 53) é que "a midiatização presente é caracterizada pelo fato de que vários campos da cultura e da sociedade são comunicativamente construídos por meio de uma variedade de mídias ao mesmo tempo”. Isso implica que é preciso considerar que as culturas estão em contato com outras formas de pensar e agir, esteja-se falando de pessoas que vivem em grandes centros urbanos ou de pescadores ribeirinhos que moram no interior da Amazônia. Existe a comunicação por meio do design vernacular, mas também existem outras, como a televisão, o rádio, o telefone móvel, a internet, que convivem simultaneamente.

Para aprofundar um pouco mais o assunto, discutem-se aqui as ideias do pesquisador Hjarvard $(2014,2015)$, que se dedica ao estudo da midiatização e da mudança social e cultural que esta acarreta. Segundo o autor, "as mídias são coprodutoras de nossas representações mentais, de nossas ações e relacionamentos com outras pessoas em uma variedade de contextos privados e semiprivados” (HJARVARD, 2014, p. 23-24), estando inseridas nas relações de instituições como a família, o trabalho, a religião, dentre outras. Isso significa que a midiatização gera uma relação de dependência em que a sociedade passa a depender dos meios de comunicação em diferentes segmentos da vida social (Ibidem).

No cenário nacional, Trindade e Perez (2016) pesquisam a midiatização e sua relação com a publicidade e os rituais de consumo. Segundo os autores, "consumidores e marcas, na circulação midiática de suas interações, têm suas zonas de contatos específicas, estratégias de usos, regras e lógicas que precisam ser estudadas” (p. 390). Isso quer dizer que o modo como ocorrem essas interações, seu contexto, sua significação na vida cotidiana, deve ser levado em consideração no cenário comunicacional atual. Em outras palavras, "a marca e suas expressões, e não apenas os formatos publicitários tradicionais, se expandem, tornando-se grandes protagonistas do consumo midiatizado e se firmam como elementos midiatizadores” (Ibidem, p. 394).

É importante delimitar, porém, que as tecnologias e sua inserção no cotidiano das comunidades não significam uma homogeneização ou um controle total da recepção, tampouco o desaparecimento de outras práticas culturais, como nos explica Martín-Barbero (2009). O autor aborda, dentre outras coisas, a importância da mestiçagem, "trama hoje de modernidade e descontinuidades culturais, deformações sociais e estruturas do sentimento, de memórias e imaginários” (Ibidem, p. 28). Esse trecho é interessante por explorar as tessituras sociais latinoamericanas, que desafiam as hipóteses fatalistas ou puristas da cultura.

Por exemplo, nesse cenário não se pode esquecer que o design vernacular convive em um mundo cercado de outras formas de comunicação que se integram ao dia a dia das pessoas, inseridas na cultura e na sociedade - um mundo midiatizado. Mesmo aquela pessoa que vive mais distante dos centros urbanos pode vir a ter acesso ao celular e à internet, assistir a programas de televisão ou ouvir conteúdos no rádio. Essa mesma pessoa pode utilizar as pinturas vernaculares para destacar seu negócio, assim como pintores de letras e paisagens em Mosqueiro (PA) podem buscar inspirações para sua arte em livros, blogs, bancos de imagens e assim por diante - ou mesmo divulgar suas pinturas nas plataformas digitais.

Pode parecer algo óbvio à primeira vista, mas se trata de tema complexo, que exige um deslocamento no modo de pensar e encarar as pessoas que 
vivem na Amazônia. Isso tem a ver com o que Martín-Barbero (2009) busca, isto é, "não o que sobrevive de outro tempo, mas o que no hoje faz com que certas matrizes culturais continuem tendo vigência” (p. 30, grifo no original). É o caso típico do design vernacular, que vem de um modo de comunicação baseado em aspectos orais e de aprendizado autodidata ou por uma relação entre mestres-aprendizes, e tem seu potencial cultural e comunicativo produzido no tempo presente da Amazônia.

Ao debater o contexto midiático local em seu livro Marca Amazônia (2016), o pesquisador Amaral Filho reflete a partir das representações simbólicas midiáticas que pautam a região enquanto um elemento instigante de consumo, analisando "a Amazônia como se fosse uma marca, isto é, como um ativo das empresas, fazendo a distinção no jogo da concorrência dos produtos e serviços” (AMARAL FILHO, 2016, p. 19). O autor trabalha sob um ponto de vista mais publicitário e mercadológico, considerando a influência do sistema capitalista e das grandes corporações que, ao se valerem da carga simbólica presente nas imagens e discursos produzidos sobre a região, passam a retratar esses valores, utilizando-os como uma espécie de vestimenta, de máscara a partir a qual o mundo irá enxergá-las. De acordo com o autor, a produção da Marca Amazônia é uma produção simbólica em larga escala, que escoa por vários aspectos da vida social.

Amaral Filho (2016) explica que "a promessa publicitária se constitui na oferta de um imaginário povoado pelo natural, a plenitude da natureza, ligada, portanto, à pureza e ao original, ordenada pelo desenvolvimento sustentável" (p. 19, grifo no original). Ao considerar o design vernacular, que possui entre seus objetivos o de atrair o consumidor e estimular o consumo, percebe-se essa promessa publicitária da qual fala Amaral Filho no processo das pinturas de paisagens. Mais do que a busca pela beleza presente na visualidade das pinturas com enfoque amazônico, também se trata por vezes de um reforço do imaginário midiático e social, e de uma tentativa de atribuir a si as características de originalidade, tradição e sustentabilidade, já que o comércio das ilhas estudadas também é voltado a turistas e visitantes.

De modo geral, o imaginário pode ser compreendido como uma forma de conhecimento, de produção da realidade, que se origina de situações vividas no mundo (DURAND, 1996). Trata-se de uma correalidade integrada, paralela, que se relaciona com o real. Sendo que o ser humano nasce com a potência do imaginário, produzindo e também sendo produzido por ele.

Sabe-se que "a cultura não é unicamente aquilo de que vivemos. Ela é também, em grande medida, aquilo para o que vivemos. Afeto, relacionamento, memória, parentesco, lugar, comunidade, satisfação emocional, prazer intelectual" (EAGLETON, 2000, p. 184). Acredita-se na cultura como um produto humano que se degrada quando a qualidade da vida da população é degradada. Ela depende da sociedade para existir. E, sendo a arte um "modo de ação produtiva do homem, ela é fenômeno social e parte da cultura” (NUNES, 1999, p. 9), ela é afetada pela cultura em transformação. Mudanças na cultura geram mudanças simbólicas.

Assim, observa-se que essa forma de comunicação, com sua matriz publicitária de venda, se inspira na cultura amazônica, mas também em outras culturas, a partir da imaginação do pintor e dos elementos presentes no imaginário coletivo, tendo estes sido criados na região ou incorporados pelo imaginário local. A possibilidade de intercâmbio cultural existe dentro das muitas realidades amazônicas. Na região existe a demarcação entre urbano e rural, uma linha tênue que não é de modo algum estática, pois "a cultura do ribeirinho se espraia pelo mundo urbano, assim como aquela é receptora das contribuições da cultura 
urbana” (PAES LOUREIRO, 2001, p. 65). Ou seja, a troca entre elementos simbólicos e materiais pertencentes a esses dois mundos é constante.

\section{A VISUALIDADE AMAZÔNICA E A PINTURA DE PAISAGENS}

Existem alguns elementos que aparecem como parte integrante do cenário amazônico urbano e rural, compondo uma paisagem colorida, atraente, que com frequência carrega o design vernacular pintado sobre sua superfície, e cujo aspecto comunicacional se revela no dia a dia local. Em vista disso, argumenta-se aqui que o design vernacular tem a potencialidade de contribuir para a visualidade amazônica - conceito utilizado por Paes Loureiro (2001) para se referir a esse cenário vibrante, diversificado e que irradia vida no qual ele próprio está inserido.

A visualidade amazônica pode ser percebida sob uma ótica de contradição das normas dominantes de "bom gosto" por conta de sua espontaneidade, do modo simples, mas intenso, no qual se materializa. Nas palavras do autor, "a visualidade amazônica celebra a glória do olhar. [...] O mundo percebido pela cor primordial, e expresso em uma forma de distorção das normas estéticas dominantes” (PAES LOUREIRO, 2008, p. 224), que geralmente apresentam menor quantidade de elementos distribuídos em sua comunicação visual. As pinturas vernaculares, ao contrário, prezam pelo uso chamativo de cores, elementos tipográficos, ilustrativos e paisagísticos, criando uma comunicação visual que dialoga com a sensibilidade das pessoas que utilizam o vernacular em sua comunicação diária.

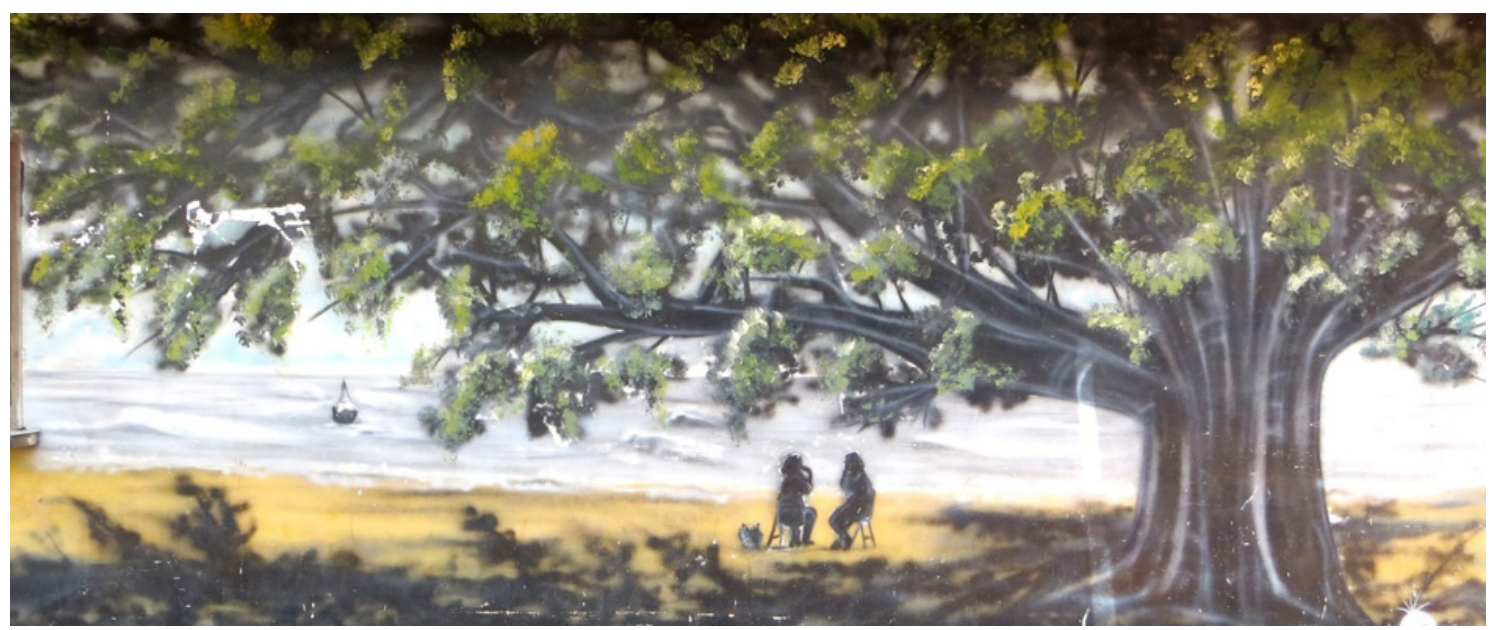

Figura 1. Paisagem pintada por Márcio (MG).

Fonte: arquivo pessoal das autoras do trabalho, 2017

Um exemplo de como a pintura de paisagens, em toda sua expressividade, pode resgatar uma história local está destacado na Figura 1, desenhada na barraca Chegada da Ilha, na praia do Chapéu Virado, em Mosqueiro - importante citar que os restaurantes na orla de Mosqueiro são conhecidos localmente como barracas, independente de seu porte físico. A pintura foi criada pelo pintor Márcio, que assinava como MG com a técnica do grafite.

Curiosas sobre a história por trás da pintura - que já se havia notado em pesquisas de campo anteriores que datam de 2015 -, perguntou-se informalmente à Fátima Pinheiro da Silva, proprietária do estabelecimento, se existia algum motivo especial para aquela cena 
estar materializada em sua fachada. De acordo com seu relato, há alguns anos as paredes da vizinhança, incluindo as externas do restaurante, foram pichadas, o que resultou em um efeito visual negativo.

Na época, Silva refletiu sobre qual seria a melhor resposta ao pichador, já que simplesmente pintar a parede não o impediria de retornar e riscar novamente a propriedade. Em outras palavras, o que ela poderia fazer para incentivar um comportamento diferente, para mostrar a esse jovem o potencial que estava desperdiçando? Segundo Silva, seus pensamentos giravam em torno de "eu tenho que fazer alguma coisa para que isso não aconteça mais” (informação verbal).

Nesse sentido, a resposta veio na forma de grafite, de arte. Ela desejava com a grafitagem dizer ao pichador "você deve fazer isso, não aquilo" (informação verbal). No lugar da pichação, Silva decidiu pintar a natureza, inspirada em uma cena paisagística que a cercava. Entre a barraca e a praia existe até hoje uma árvore imensa, e embaixo dela três amigas costumavam sentar e passar o tempo. Silva fotografou a cena e contratou o grafiteiro MG para a recriação da imagem na fachada no ano de 2012.

A pintura já foi revitalizada pelo mesmo pintor. Nela é possível observar que o pintor MG teve cuidado em manter certos aspectos da natureza local na imagem desenhada; por exemplo, as águas de Mosqueiro vêm de rios, portanto, sua cor se assemelha ao cinza e ao castanho, como na pintura. Também aparece um barco na imagem, elemento tradicional na visualidade amazônica, no cenário da cultura ribeirinha, que apresenta relação intrínseca com os rios. Sem contar a riqueza de detalhes que o artista deu à natureza representada na pintura, transpondo a imponência da árvore pertencente à paisagem real para sua paisagem ideal.

A seguir, a Figura 2 traz outra imagem de autoria do pintor $\mathrm{MG}^{2}$. Após contar sua história, Silva nos levou a uma parte distinta da barraca, onde é possível encontrar a paisagem representada na Figura 2 no interior do restaurante, também inspirada na natureza encontrada na praia do Chapéu Virado, em Mosqueiro.

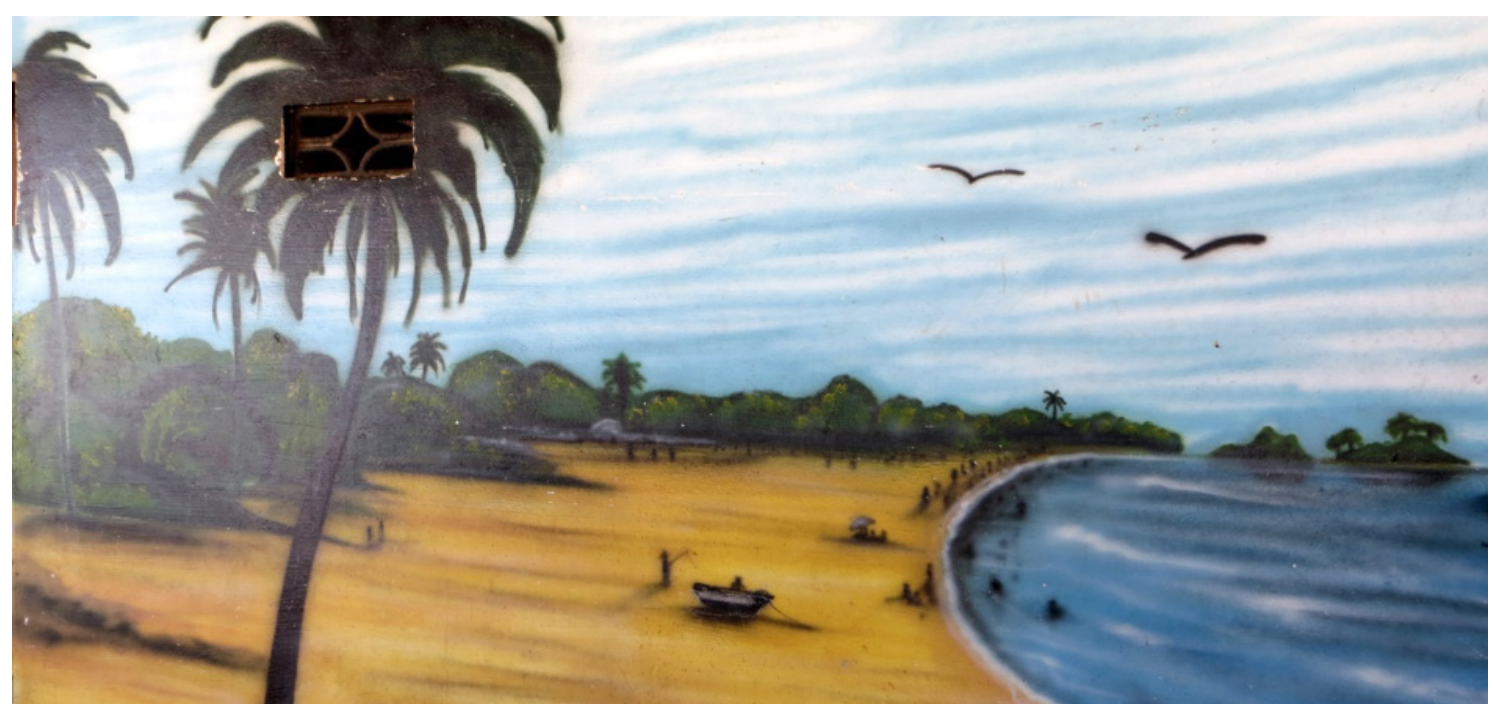

Figura 2. Paisagem pintada por Márcio (MG).

Fonte: arquivo pessoal das autoras do trabalho, 2017

2. Infelizmente, quando se vai a campo, não se sabe o que irá ser descoberto. Márcio faleceu em 2016, deixando para trás, além de familiares e amigos, resquícios do seu talento e da sua arte. 
Aqui começam a aparecer elementos que se diferenciam da realidade visual da praia. Por exemplo, por que a escolha de representar a água da praia por meio da cor azul se as águas dos rios amazônicos na ilha são cor de terra? O mar azul pertence aos filmes, novelas, séries, livros, fotografias, mas não é essa a cor da água local, onde as pessoas se banham e criam relações. Trata-se então de uma representação mais midiática da água. É preciso ressaltar que existem exemplos de águas claras na Amazônia, como o caso do Rio Tapajós, onde o solo claro e as águas cristalinas podem refletir a cor do céu. Porém esse não é o caso das praias que banham a ilha aqui estudada. Como se discutiu anteriormente, a midiatização busca compreender exatamente fenômenos como esse, em que a presença da mídia no cotidiano impacta em uma mudança cultural e social (HEPP, 2014).

Além disso, a praia do Chapéu Virado possui uma orla que circula grande parte da ilha e não aparece com clareza na pintura. Essa orla é asfaltada, perpassa diversos restaurantes, pousadas e residências, possuindo tráfego de veículos automotivos e, dependendo da data, poluição sonora; de certo modo, a representação da praia na paisagem é mais tranquila, com mais natureza e menos estruturas comerciais, como bares e restaurantes.

Nesse caso é possível perceber o uso da Marca Amazônia (AMARAL FILHO, 2016), mesmo que inconscientemente, pela barraca. O nome Chegada da Ilha é sugestivo, e as imagens, sempre refletindo um lugar tranquilo, pacífico, paradisíaco, retomam aspectos positivos geralmente ligados, a partir de um olhar exógeno, à Amazônia.

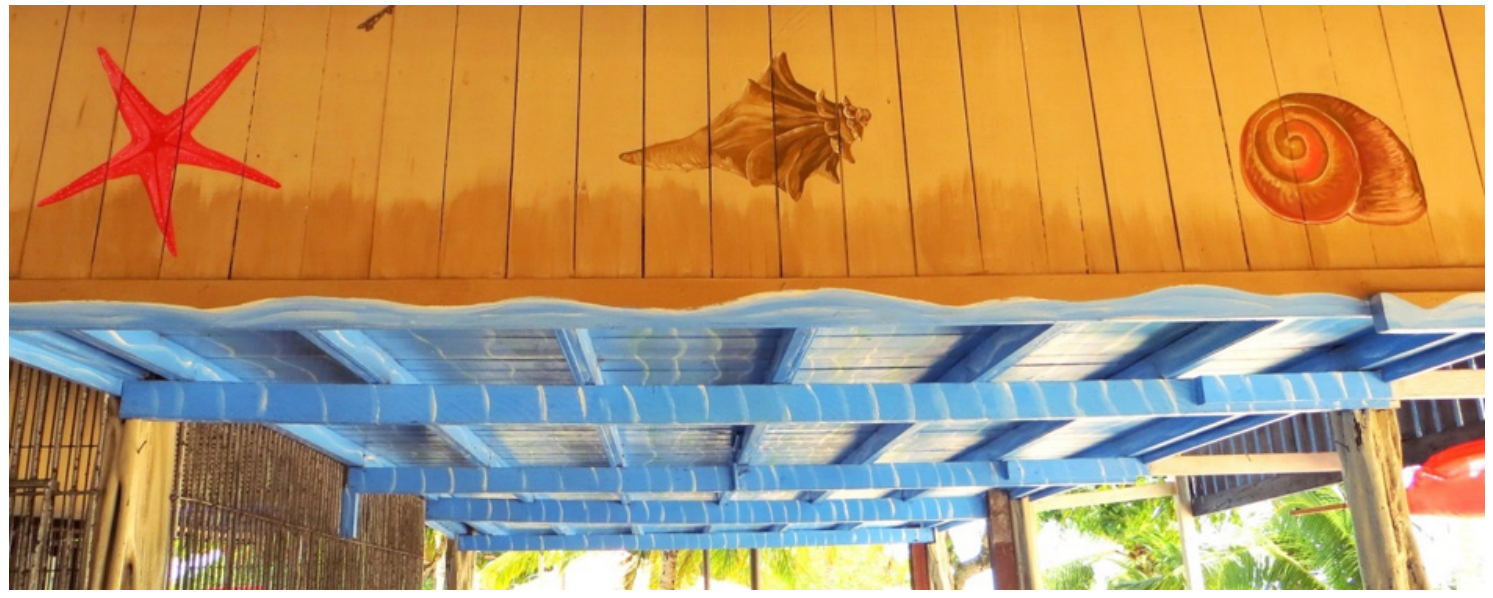

Figura 3. Paisagem pintada por André Penha.

Fonte: arquivo pessoal das autoras do trabalho, 2017.

Outro exemplo que se gostaria de destacar aqui é o da barraca 0 Azulão, localizada na Praia do Farol (Figura 3). Trata-se de uma barraca que, na época da pesquisa de campo, havia mudado de administração recentemente e, portanto, ainda estava sendo pintada e estilizada de acordo com as ideias dos novos donos. Conversou-se com a proprietária Aline Raiol Azevedo, que antes trabalhava como gerente de supermercado em Belém, e em 2017 mudou sua rotina ao alugar a barraca e criar O Azulão.

Conforme se pode observar na Figura 3, o tema que está sendo construído se inspira na ideia de praia, preferindo assim focar em elementos mais calmos que combinem com as águas e com a natureza, por isso o uso de azul, bege, rosa e dourado, cores harmônicas em relação à 
paisagem local, mas que ainda permitem que $O$ Azulão se destaque frente às barracas vizinhas. As pinturas foram feitas pelo primo de Azevedo, André Penha, que está começando a atuar na profissão. O interessante da paisagem da barraca é a mistura de ideais paisagísticos, ao colocar em um mesmo espaço tanto a natureza amazônica quanto referências exógenas, como mostrado a seguir.

Na Figura 3, O Azulão traz elementos praianos como a estrela-do-mar, as conchas e um teto cuja pintura simula ondas azuis, elementos exógenos que pertencem às imagens encontradas em filmes hollywoodianos, séries televisivas e outros. Ao caminhar pela areia das praias de Mosqueiro, não são estrelas-do-mar ou conchas desse tipo que serão encontradas, mas, sim, sementes e cascas de árvores locais, gravetos e outros sedimentos que não aparecem na representação hegemônica de praia.

Conforme colocado, Trindade e Perez (2016) refletem sobre a importância dos rituais de consumo na sociedade atual, enquanto Hjarvard (2014) descreve a inserção da mídia em instituições como a família e o trabalho. $O$ ato de sentar na sala de estar com a família e assistir a filmes na televisão ou vídeos no celular tem significado e importância social. Isso se traduz no fato de que a imagem de uma estrelado-mar parece ser mais "natural" à paisagem litorânea do que a de uma semente de andiroba (árvore local), por exemplo. Essa situação tem a ver com os impactos da midiatização e dos rituais de consumo atuais.

No momento em que as referências que chegam são sempre exógenas, destacando aspectos que não necessariamente se enquadram naquele contexto, as mensagens passam a se normalizar no imaginário. As imagens destacadas no artigo apresentam em sua maioria figuras humanas. $\mathrm{Na}$ pesquisa da dissertação, porém, muitas vezes a representação do ser humano é feita a partir de objetos, como barcos, barracas, utensílios. A ausência de pessoas ou da diversidade presente no cotidiano da população amazônica, reforçada pelos meios de comunicação de massa, muitas vezes é incorporada nas criações vernaculares.

Ao mesmo tempo, O Azulão traz outra paisagem do lado de fora da barraca, dessa vez uma mistura do estereótipo ribeirinho com elementos exógenos, conforme visto a seguir (Figura 4).

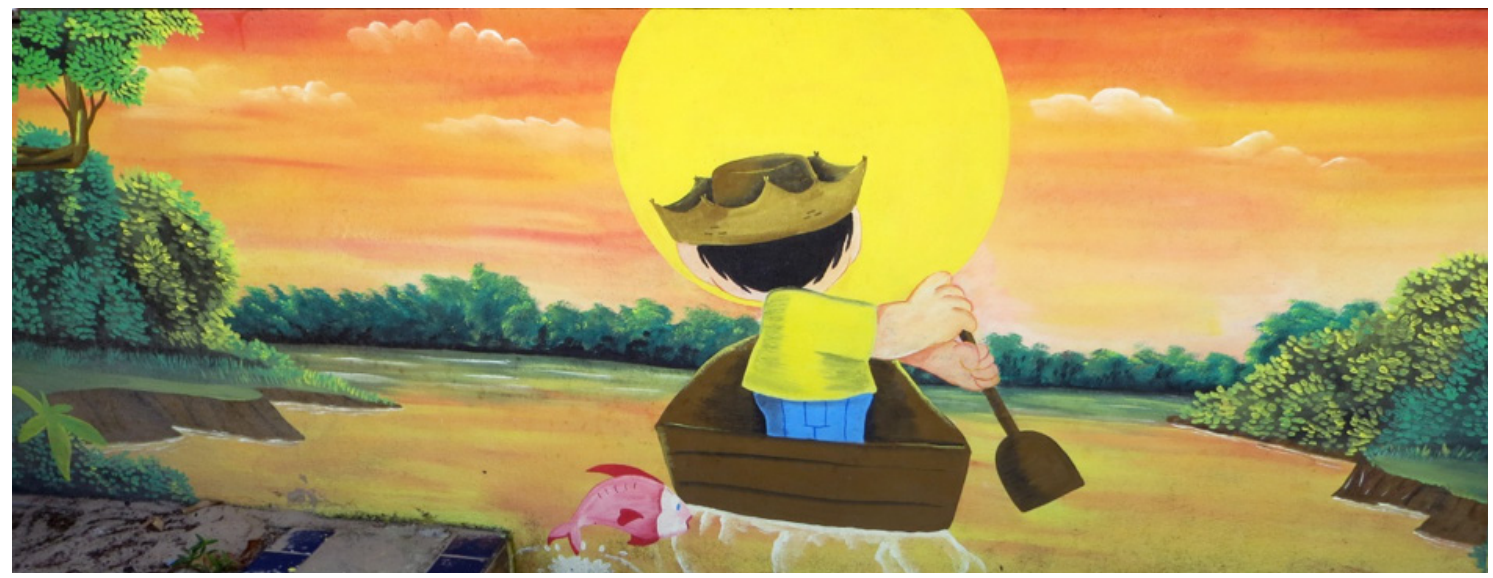

Figura 4. Paisagem pintada por André Penha.

Fonte: arquivo pessoal das autoras do trabalho, 2017.

Trata-se de uma pintura em que as águas são amarronzadas e esverdeadas, da cor dos rios locais, mas existe um elemento do imaginário nacional, midiatizado, representado aqui na figura do Chico Bento, 
personagem criado por Mauricio de Sousa. Chico Bento é a encarnação de uma pessoa humilde, que vive no interior em uma fazenda. Seus quadrinhos não se passam na Amazônia, mas o artista fez uma ligação entre as características interioranas do personagem e a figura do caboclo amazônico.

Então se pode observar que na mesma barraca existe essa dualidade, o diálogo entre o imaginário local e o imaginário exterior. Pode-se ir além, quando estudos (BOYER, 1999; CASTRO, 2013) afirmam que a própria figura do caboclo amazônico foi uma construção exógena, de caráter depreciativo, que visava inferiorizar as pessoas que viviam na região.

Assim, a fotografia na Figura 4 mostra a vida ribeirinha, a canoa amazônica, o pôr do sol no rio, os animais e demais elementos da natureza, além da figura midiatizada do caboclo amazônico em destaque. São exemplos que excluem dessas representações o restante da vida social: o problema com o lixo e a sujeira nas ruas e praias, a violência, o processo de urbanização e o consequente desmatamento das localidades, os engarrafamentos, a poluição sonora, entre outros.

Essas imagens precisam ser discutidas por conta da forte presença de estereótipos que apresentam. Ao retratar uma face da vida amazônica marcada pelo olhar do colonizador, excluindo assim outros modos de ver e perceber essa realidade, o enfoque é colocado em elementos hegemônicos do imaginário sobre a Amazônia, com destaque para a natureza, a harmonia, a passividade, a docilidade e a tranquilidade. Essa visão contrasta com a experiência endógena e com a vivência urbana que esses lugares estão processando atualmente.

Por isso a importância de dialogar com os conceitos de mediação e midiatização, para que seja possível compreender as mudanças no cenário comunicacional atual a partir da inserção das mídias no cotidiano (HEPP, 2014; HJARVARD, 2014; TRINDADE; PEREZ, 2016), e o modo como elas podem interferir no imaginário e nas representações locais. A partir disso, podem ser pensadas atitudes e medidas que fortaleçam e valorizem as práticas comunicacionais e culturais da região.

\section{CONCLUSÃO}

$\mathrm{O}$ artigo buscou responder de que forma o design vernacular, a partir da pintura de paisagens em Mosqueiro, expressa a cultura amazônica. Para isso, foi necessária a realização de uma contextualização sobre o design vernacular e sua materialização na região, além do diálogo com alguns conceitos que se entrelaçam com a temática.

Foi abordado o conceito de paisagem com base nos estudos de Moreira (2012), que mostrou que não apenas a paisagem real, concreta, pode ter influência na vida social das pessoas, mas a paisagem ideal, abstrata e imaginada, também possui uma carga significativa capaz de impactar o mundo físico do qual faz parte. Também se realizou um diálogo com a estética da comunicação a partir da visão de Martino (2007), que discute como a comunicação se espraia pelas diversas faces do cotidiano humano.

Além disso, foi necessário mergulhar em outras águas, como as que banham os temas da mediação e da midiatização, pois se trata de teorias centrais para o desenvolvimento do trabalho, uma vez que se verificou que a cultura amazônica retratada nas pinturas apresenta tanto aspectos endógenos, que representam as dinâmicas locais, quanto inspirações exógenas, que se fazem hegemônicas através dos meios de comunicação 
de massa e do fenômeno da midiatização. Trouxe-se para a discussão os autores internacionais Martín-Barbero (2004, 2009), Hepp (2014) e Hjarvard (2014, 2015), mas também autores nacionais através de Trindade e Perez (2016). A contribuição teórica desses autores tornou possível compreender um pouco mais o contexto midiático atual e, a partir das mediações comunicacionais da cultura, como isso perpassa o design vernacular.

Para falar de Amazônia, é preciso fazer um contraponto com autores locais que conhecem a região e suas particularidades. O artigo se embasou nos estudos de Amaral Filho (2016) - que apresenta o conceito de Marca Amazônia e como a publicidade e o consumo em larga escala se apropriam das qualidades imaginárias da região para integrá-las a produtos e serviços - e em Benedito Nunes (1999) e Paes Loureiro (2001, 2008), que ajudaram a dar consistência à discussão.

No início da pesquisa, antes da viagem a campo, esperava-se encontrar registros mais próximos da realidade local, que compreendessem a experiência tradicional, suas características endógenas. Mas durante a viagem observou-se que a materialização desse imaginário traz elementos plurais, endógenos e exógenos, que se entrelaçam nas histórias contadas nas pinturas. Por tudo o que foi visto, ressalta-se que não se pode esperar que as pinturas representem somente as tradições locais, mesmo que o fazer vernacular se assente sobre uma tradição cultural. A cultura é movente, adaptável e a comunicação vernacular se adequa às necessidades reais da comunidade em que surge.

Ressalta-se a importância de que mais pesquisas se proponham a mostrar essa realidade como acontece nas ruas, para que seja possível a longo prazo reduzir os estereótipos - por vezes nocivos - que circulam nos meios de comunicação de massa e que o conhecimento e a cultura gerados na região possam ser reconhecidos em sua pluralidade.

\section{REFERÊNCIAS}

AMARAL FILHO, O. Marca Amazônia: o marketing da floresta. 1. ed. Curitiba: CRV, 2016.

BOYER, V. O pajé e o caboclo: de homem a entidade. Mana, Rio de Janeiro, v. 5, n. 1, p. 29-56, 1999. Disponível em: <https://goo.gl/ngipsX>. Acesso em: 29 nov. 2017.

CASTRO, F. F. A identidade denegada. Discutindo as representações e a autorrepresentação dos caboclos da Amazônia. Revista de Antropologia, São Paulo, v. 56, n. 2, p. 432-475, 2013. Disponível em: <https://goo.gl/xHhJXX>. Acesso em: 29 nov. 2017.

DURAND, G. Campos do imaginário. Lisboa: Instituto Piaget, 1996.

EAGLETON, T. A ideia de cultura. Tradução Sandra Castello Branco. São Paulo: Unesp, 2000

HEPP, A. As configurações comunicativas de mundos midiatizados: pesquisa da midiatização na era da "mediação de tudo". MATRIZes, São Paulo, v. 8, n. 1, p. 45-64, jan./jun. 2014. Disponível em: <https://goo.gl/cdvkNp>. Acesso em: 16 abr. 2018.

HJARVARD, S. Midiatização: conceituando a mudança social e cultural. MATRIZes, São Paulo, v. 8, n. 1, p. 21-44, jan./jun. 2014. Disponível em: <https://goo.gl/vjeFmi>. Acesso em: 16 abr. 2018.

Da mediação à midiatização: a institucionalização das novas mídias. Parágrafo, São Paulo, v. 3, n. 2, p. 51-62, jul./dez. 2015. Disponível em: <https://goo.gl/61N6qq>. Acesso em: 16 abr. 2018.

MARTÍN-BARBERO, J. Ofício de cartógrafo: travessias latino-americanas da comunicação na cultura. São Paulo: Edições Loyola, 2004.

Dos meios às mediações: comunicação, cultura e hegemonia. 6. ed. Rio de Janeiro: UFRJ, 2009.

MARTINO, L. M. S. Estética da comunicação: da consciência comunicativa ao "eu" digital. Petrópolis: Vozes, 2007 
MARTINS, F. O. Letras que flutuam: o abridor de letra e a tipografia vitoriana. 2008. $89 \mathrm{f}$. Monografia (Especialização em Semiótica e Cultura Visual) - Instituto de Ciências da Arte da Universidade Federal do Pará, Belém, 2008.

MOREIRA, E. Uma geografia especial. In: . Ideias para uma concepção geográfica da vida. Belém: Semec, 2012. p. 69-175.

NUNES, B. Introdução à filosofia da arte. 4. ed. São Paulo: Ática, 1999.

PAES LOUREIRO, J. de J. Cultura amazônica: uma poética do imaginário. São Paulo: Escrituras, 2001. (Coleção Obras Reunidas).

. A arte como encantaria da linguagem. São Paulo: Escrituras, 2008. (Coleção Ensaios Transversais).

PEREIRA, N. C. R. Traços urbanos da Amazônia: o que o design vernacular tem a dizer sobre a cultura local. 2014. 125 f. Trabalho de Conclusão de Curso (Bacharelado em Publicidade e Propaganda) - Universidade Federal do Pará, Belém, 2014. Disponível em: <https://goo.gl/e1ry8F>. Acesso em: 25 abr. 2017.

PEREIRA, N. C. R.; AMORIM, C. R. T. C. Design vernacular como potencialidade de comunicação na Amazônia urbana. In: CONGRESSO BRASILEIRO DE CIÊNCIAS DA COMUNICAÇÃO, 39., 2016, São Paulo. Anais... São Paulo: Intercom. Disponível em: <https://goo.gl/DwimDw>. Acesso em: 10 ago. 2017.

TRINDADE, E.; PEREZ, C. Para pensar as dimensões do consumo midiatizado: teoria, metodologia e aspectos empíricos. Contemporanea - Revista de Comunicação e Cultura, Salvador, v. 14, n. 3, p. 385-397, set./dez. 2016. Disponível em: <https://goo.gl/Ywqc7S>. Acesso em: 16 abr. 2018. 